\title{
Pengaruh Konsentrasi dan Waktu Aktivasi Katalis Palladium pada Electroless Plating Nickel Permukaan Plastik ABS
}

\author{
Muhammad Budi Nur Rahman ${ }^{a}$, Sunardi ${ }^{b}$, Auliandi Luthfi Wibisono ${ }^{c}$, Bayu Anggara ${ }^{d}$ \\ a,b,c,d Program Studi Teknik Mesin, Fakultas Teknik, Universitas Muhammadiyah Yogyakarta \\ Jl. Brawijaya, Tamantirto, Kasihan, Bantul, Yogyakarta, Indonesia 55183 \\ Telepon/fax (0274) 387656/ (0274) 387646 \\ e-mail: budinurrahman@umy.ac.id ${ }^{a}$
}

\begin{abstract}
ABS plastic is widely used for automotive components and interior design because of its lightweight, easily shaped, strong, but low hardness, no frictionresistant, and heat resistant. Electro less plating is a method of metallization before electro plating to improve the quality and appearance. To get a good bond between plastic and metal is necessary to the activation of the palladium which is influence by concentration, temperature and activation time. The research aims to determine the influence of the palladium solution concentration and activation time of the electroless nickel plating process on surface roughness, layer thickness, hardness and wear resistance of ABS plastic. The concentration of palladium was prepared at $3 \%, 5 \%$ and $7 \%$ in $\mathrm{HCl}$ solution (37\%). The activation time was carried out during 4 to 12 minutes. The research shows that those parameters increase wear resistance of the surface. In addition the activation time parameter is also found to increase layer thickness and roughness value of the specimens. Yet, those parameters are not found to affect significantly on its hardness value.
\end{abstract}

Abstract

Keywords: electroless plating nickel, ABS plastic, palladium concentration, activation time

\section{Pendahuluan}

Plastik merupakan material yang dapat digunakan sebagai bahan pengganti logam sehingga plastik disebut engineered material. Hal ini disebabkan material tersebut mempunyai kelebihan, seperti ringan, tahan korosi, dan harganya relatif murah. Plastik memiliki beberapa jenis, seperti polyethylene, teflon, polysulfone, polypropylene, acrylonitrile-butadine-styrene (ABS), dan lain sebagainya [1]. Plastik ABS merupakan material yang paling banyak digunakan untuk pelapisan nikel. Selain itu, plastik ABS merupakan engineering thermoplastic yang mengandung 3 monomer. Acrylonitrile bersifat tahan terhadap bahan kimia dan stabil terhadap panas. Bagian butadine terdistribusi secara merata pada matriks akrilonitril-stirena membuat plastik ABS memiliki keunggulan, seperti logam lebih mudah menempel ke substrat dengan baik, koefisien ekspansi termal rendah, kemudahan pencetakan, dan penampilan estetika meningkat [2]. Di sisi lain, styrene menjamin kekakuan (rigidity) dan membuat plastik mudah diproses. Tidak semua plastik ABS memiliki tingkat keberhasilan yang tinggi untuk dilapisi sehingga untuk menghindari kegagalan pemilihan plastik ABS dengan standar plating grade. Di balik keunggulan yang dimiliki, plastik ABS memiliki beberapa kelemahan, di antaranya kekerasan yang kurang tinggi, ketahanan gesek, dan pada suhu rendah mudah mengalami kerusakan. Untuk mengatasi kekurangan ini, salah satu metode yang digunakan yaitu pelapisan nikel dengan metode electrolessplating. Electroless plating merupakan metode palepisan logam yang tidak menggunakan listrik pada prosesnya, tetapi dengan reaksi oksidasi dan reduksi pada permukaan substrat dengan larutan garam elektrolit logam pelapis untuk membentuk lapisan [3]. Pelapisan logam tersebut akan membuat plastik ABS memiliki sifat mekanik seperti 
meningkatkan kekerasan, ketebalan, sifat menghantar listrik, tahan terhadap abrasi, dan korosi, serta tahan cuaca serta memberikan kesan logam atau metallic appearance [4].

Plastik ABS dapat dietsa secara kimiawi dengan mudah dibandingkan dengan jenis plastik lainnya karena bagian butadine terdistribusi secara merata pada matriks akrilonitrilstirena sehingga ketika dietsa secara kimiawi dengan chromic acid partikel butadiena akan larut dan meninggalkan permukaan yang berpori sehingga permukaan akan lebih mudah di metalisasi. Di pasaran, proses pelapisan yang dilakuan biasanya menggunakan metode spray coating. Hasil dari metode ini memiliki kekurangan di antaranya lapisan mudah mengelupas, cepat pudar dalam waktu yang relatif singkat, dan ketebalan yang tidak merata serta lapisan yang dihasilkan terbatas. Oleh karena itu, metode electroless plating nikel untuk pelapisan plastik ABS agar didapatkan pelapisan nikel yang lebih baik dari metode coating lainnya.

Proses electroless plating sangat tergantung pada tahap etsa dan aktivasi yang merupakan tahap paling penting pada pelapisan plastik. Tahap etching berfungsi mengikis permukaan plastik ABS agar terbentuk pori-pori [5]. Pori-pori berfungsi untuk meningkatkan daya lekat lapisan dan lebih memudahkan palladium menempel pada permukaan. Etching dilakukan dengan menggunakan hydrogen peroksida $\left(\mathrm{H}_{2} \mathrm{O}_{2}\right)$ dan asam sufat $\left(\mathrm{H}_{2} \mathrm{SO}_{4}\right)$ Lalu pada tahap aktivasi atau metalisasi, logam palladium mengendap dan melekat pada permukaan plastik yang berpori sehingga menjadikan plastik bersifat konduktif sebagai katalisator pada proses pelapisan electrolessplating. Penelitian lain menyebutkan bahwa penambahkan ion palladium pada tahap etsa dapat meningkatkan absorpsi palladium [6]. Semakin kecil ukuran partikel palladium, semakin mudah aktivasi terjadi pada permukaan plastic sehingga konsentrasi katalis palladium sangat mempengaruhi hasil pelapisan karena dengan meningkatnya kadar palladium yang digunakan, logam yang menempel pada plastik akan lebih banyak dan berdampak pada hasil yang maksimal. Beberapa penelitian terdahulu $[3,4,5,6]$ belum banyak menunjukan hubungan parameter proses dengan sifat mekanis dari permukaaan lapisan. Penelitian ini membahas pelapisan permukaan plastik ABS dengan metode electroless platting dan mengamati pengaruh parameter prosesnya terhadap sifat fisik dan mekanik dari hasil pelapisan tersebut.

\section{Metode}

\subsection{Proses Electroless Plating}

Proses electrolessplating dibagi menjadi beberapa tahapan antara lain:

1. Tahap pembersihan permukaan benda spesimen menggunakan larutan soak cleaning yang terbuat dari sodium karbonate $\left(\mathrm{Na}_{2} \mathrm{CO}_{3}\right)$ dan trisodium phospat $\left(\mathrm{Na}_{3} \mathrm{PO}_{4}\right)$ dipanaskan pada tempetature $50-70^{\circ} \mathrm{C}$ dengan waktu proses 5 menit. Tahap ini bertujuan menghilangkan berbagai bahan pengotor dan membersihkan permukaan plastik ABS.

2. Tahap Etching berfungsi membentuk pori-pori dan membuat permukaan menjadi kasar dalam skala mikro pada permukaan plastik ABS dengan mengikis permukaan menggunakan larutan kimia berupa asam kromat atau kromium. Hal ini akan meningkatkan adhesi mekanik, mengubah sifat permukaan dari bahan hidrofobik menjadi hidrofilik, dan menciptakan pori-pori mikro yang bertindak sebagai tempat ikatan antara subtrat plastik dan logam [7]. Tahap ini menggunakan larutan chemical etching berupa asam kromat $\left(\mathrm{H}_{2} \mathrm{CrO}_{4}\right) 300 \mathrm{gr}$ dan asam sulfat $\left(\mathrm{H}_{2} \mathrm{SO}_{4}\right) 18 \mathrm{ml}$ dengan suhu antara $60-70^{\circ} \mathrm{C}$ dengan waktu 30 menit.

3. Tahap netralisasi berungsi menghilangkan sisa-sisa kromium dari proses etsa yang masih mengendap pada pori-pori permukaan plastik ABS. Hal ini diperlukan karena sisa kromium yang terdapat pada pada pori-pori permukaan plastik $A B S$ dapat menghambat proses electroless. Tahap ini menggunakan larutan netralisasi berupa sodium sulfit $\left(\mathrm{Na}_{2} \mathrm{SO}_{3}\right)$ dan ditambahkan aquades hingga 1 liter dengan suhu ruangan dan waktu proses 1 menit.

4. Tahap pre-dip berfungsi menghilangkan bekas larutan etsa yang masih ada di permukaan plastik ABS secara menyeluruh dan meningkatkan efisiensi reaksi kimia pada tahap katalisasi. Bahan dan kondisi larutan yang digunakan yaitu PS pre-dip A yang terbuat dari $\mathrm{HCl} 37 \%$ sebanyak 100ml dan ditambahkan aquades hingga 1 liter pada suhu ruangan dan waktu proses 1 menit. 
5. Tahap katalisasi berfungsi menghasilkan permukaan plastik ABS yang bersifat katalis. Permukaan plastik dinyatakan telah bersifat katalis jika permukaan plastik tersebut terlapisi palladium. Bahan yang digunakan yaitu PS katalis $1 \mathrm{~A}$ terbuat dari campuran $\mathrm{PdCl}_{2} / \mathrm{SnCl}_{2}$ sebanyak 3\%, 5\%, dan $7 \%$. Bahan ini kemudian dicampur $\mathrm{HCl} 37 \%$ sebanyak $200 \mathrm{ml}$ dan ditambahkan aquades hingga larutan menjadi 1 liter dengan suhu ruangan dan waktu proses 6 menit. Pada penelitian lain, suhu ruangan dan variasi waktu proses $4,6,8,10$, dan 12 menit dengan konsentrasi $3 \%$. Perlu diketahui bahwa $\mathrm{HCl} 37 \%$ sebaiknya dilarutkan terlebih dahulu dengan aquades, kemudian dicampur dengan PS katalis $1 \mathrm{~A}$.

6. Tahap akselerasi berfungsi melarutkan dan menghilangkan lapisan timah tipis yang menutupi palladium. Lapisan timah dapat menghambat terbentuknya lapisan logam pada saat electroless plating berlangsung. Fungsi lainnya yaitu membersihkan pencemar yang masih berada di permukaan benda kerja yang dapat mengurangi efektivitas reaksi ketika proses electroless plating dan dapat merusak kualitas. Tahapan ini menggunakan larutan PS akselerator A berupa campuran sodium hydrosida $(\mathrm{NaOH})$, tembaga sulfat $\left(\mathrm{CuSO}_{4}\right)$ dan ethylene diamine tetraacetic acid disodium $\left(\mathrm{EDTANa}_{2}\right)$ sebanyak $210 \mathrm{ml}$ dengan suhu ruangan dan waktu proses 5 menit.

7. Tahap electrolessplating dilakukan untuk menghasilkan lapisan logam yang menjadi lapisan dasar konduktor agar benda kerja dapat terlapisi logam lain pada tahap electroplating. Proses pelapisan menggunakan larutan berupa campuran nikel sulfat $\left(\mathrm{NiSO}_{4}\right)$, amonium klorida $\left(\mathrm{NH}_{4} \mathrm{Cl}\right)$, sodium hydrogen phospate $\left(\mathrm{Na}_{2} \mathrm{HPO}_{4}\right)$, dan sodium hidroksida $(\mathrm{NaOH})$ dicampur aquades hingga 1 liter dengan suhu $65-70^{\circ} \mathrm{C}$ dan waktu proses 8 menit.

\subsection{Proses Pengujian}

1. Pengujian kekerasan menggunakan shore tipe $D$ untuk mengukur material nonlogam yang keras seperti ebonite, resin keras, akrilik, kaca, piringan cetak, dan fiber. Pengukuran kekerasan dengan menghitung resistansi material dari penetrasi yang diberikan oleh jarum ke dalam spesimenn dengan beban yang sudah diinginkan.

2. Pengujian kekasaran menggunakan alat Surface Roughness Tester DR220

3. Pengujian keausan menggunakan metode Ogoshi, spesimen akan diberi beban gesek dari cincin yang diputar (revolving disc). Pembebanan ini akan menghasilkan kontak berulang-ulang pada spesimen sehingga sebagian material yang ada permukaan benda uji terlepas.

4. Pengukuran ketebalan lapisan dapat dilihat dengan pengamatan visual dengan foto mikro terhadap spesimen yang telah dilapisi. Pengamatan menggunakan Metallurgycal Miroscope Olympus BX53M.

5. Pengamatan rekatan antara bahan plastic dengan lapisan nikel menggunakan SEM.

\section{Hasil dan Pembahasan}

\subsection{Kekasaran Permukaan}

Pengujian kekasaran permukaan lapisan menggunakan alat Surface Roughness Tester DR220. Pengujian kekasaran bertujuan mengetahui tingkat kekasaran masing-masing spesimen. Data hasil pengujian kekasaran permukaan spesimen setelah proses electroless plating dapat dilihat pada Gambar 3.1.

Berdasarkan Gambar 3.1.a, bertambahnya konsentrasi palladium sedikit menurunkan kekasaran permukaan. Pada konsentrasi $3 \%$, nilai kekasarannya $0,525 \mu \mathrm{m}$ dan semakin menurun pada variasi $5 \%$ sebesar $0,522 \mu \mathrm{m}$ dan pada konsentrasi $7 \%$ sebesar $0,506 \mu \mathrm{m}$. Gambar 3.1.b menjelaskan bahwa pengaruh waktu aktivasi terhadap kekasaran permukaan setelah proses electrolessplating nikel. Dari gambar tersebut, diketahui bahwa semakin lama waktu aktivasi, kekasaran permukaan juga semakin turun. Pada waktu aktivasi 4 menit, kekasaran sebesar $0,840 \mu \mathrm{m}$ sampai waktu aktivasi 12 menit kekasaran permukaan sebesar $0,556 \mu \mathrm{m}$. 


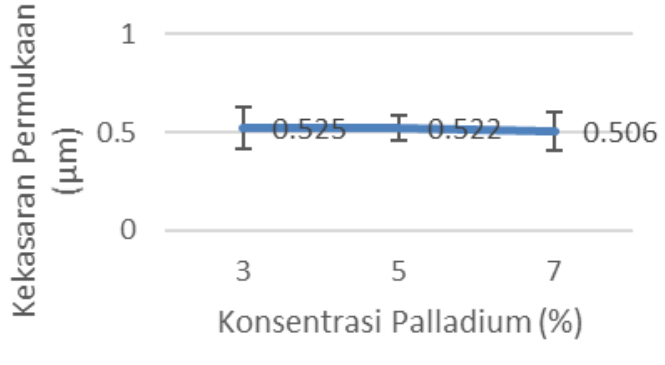

(a) Pengaruh konsentrasi larutan aktivasi palladium

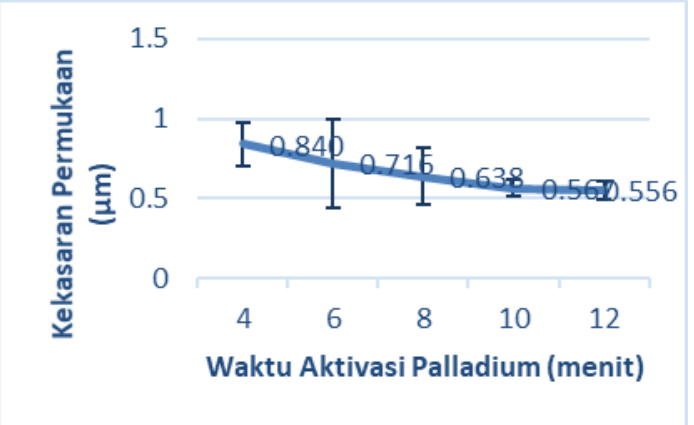

(b) Pengaruh waktu aktivasi dalam larutan palladium

Gambar 3.1 Nilai kekasaran permukaan setalah proses elektrolessplating nikel pada plastic ABS

Penambahan konsentrasi dan waktu aktivasi katalis palladium menyebabkan ion-ion yang menempel pada permukaan plastik bervariasi karena proses aktivasi memengaruhi banyaknya logam nikel yang dapat terdeposisi ke permukaan plastik. Hal ini akan memengaruhi kekasaran dari lapisan yang akan dihasilkan pada saat elektroles plating berlangsung selain suhu kerja optimal dari larutan. Berdasarkan kondisi tersebut, proses pre-treatment yang baik serta suhu kerja yang optimal akan membuat ion-ion nikel pada larutan electrolessplating menempel dengan maksimal pada permukaan plastik ABS yang sudah diaktifkan dengan katalis paladium.

\subsection{Ketebalan Lapisan}

Pengamatan ketebalan lapisan dilakukan menggunakan alat Metallurgycal Microscope Olympus BX53M seperti pada Gambar 3.2. Pengukuran ketebalan dilakukan dengan mengambil posisi pada 3 titik untuk setiap spesimen. Hasil pengamatan dan pengukuran ketebalan dapat dilihat pada Gambar 3. Peningkatan konsentrasi larutan aktivasi palladium dan lama waktu aktivasi akan meningkatkan ketebalan lapisan. Pada pengukuran ketebalan, lapisan dengan konsentrasi $3 \%$ nilai ketebalan lapisan yaitu $1.23 \mu \mathrm{m}$ dan semakin meningkat pada konsentrasi $5 \%$ dan $7 \%$ sebesar $1,38 \mu \mathrm{m}$ dan 1,82 $\mu \mathrm{m}$ seperti pada Gambar 3.a. Dapat diketahui, bahwa pelapisan nikel dengan variasi konsentrasi katalis palladium ini terjadi peningkatan ketebalan seiring meningkatnya konsentrasi katalis palladium. Temperatur memengaruhi cepat lambatnya gerakan elektron dari ion positif menuju ke ion negatif sehingga ion nikel yang mengendap di permukaan bahan semakin bertambah dan menyebabkan bertambahnya ukuran kristal. Temperatur dan kadar logam nikel pada larutan yang digunakan pada proses pelapisan juga berdampak ketebalan lapisan nikel [8]. Pengendapan ion pada permukaan plastik akan berdampak terhadap bertambahnya ketebalan lapisan nikel pada spesimen sehingga berat spesimen juga akan bertambah. Katalis palladium juga memiliki peran penting dalam ketebalan lapisan karena akan memengaruhi banyaknya logam nikel yang menempel.

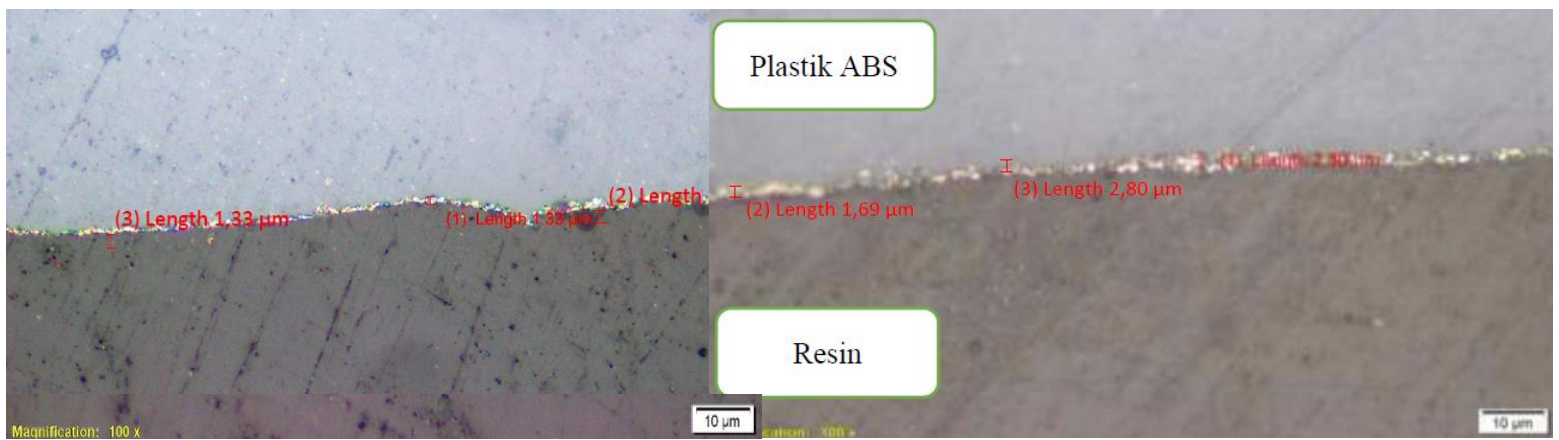

(a) Konsentrasi aktivasi 5\% palladium

(b) Waktu aktivasi palladium 10 menit

Gambar 3.2. Foto pengamatan mikroskop untuk menghitung ketebalan lapisan elektrolessplating 


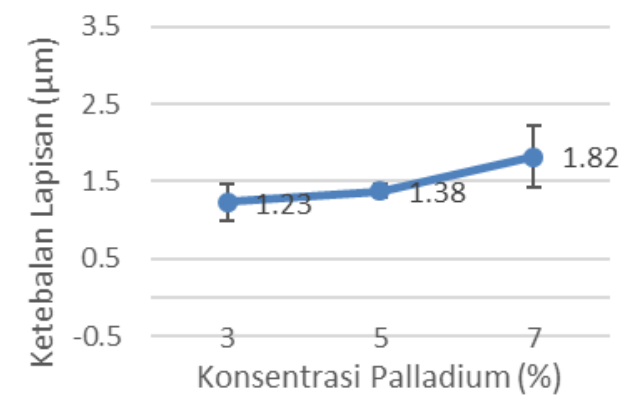

(a) Pengaruh konsentrasi larutan aktvasi palladium

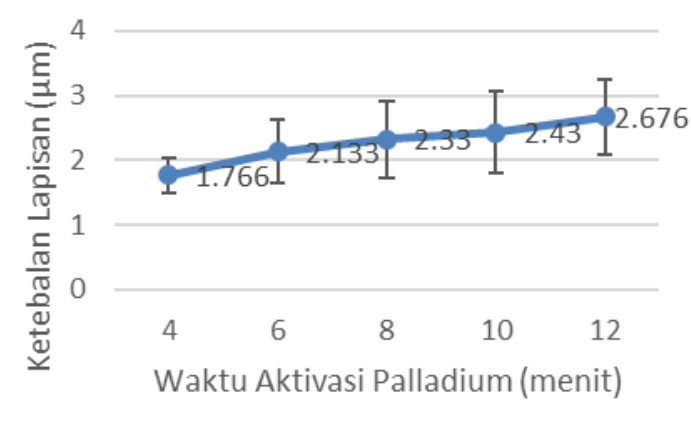

(b) Pengaruh waktu aktivasi pada larutan palladium

Gambar 3. Ketebalan lapisan setelah proses elektrolessplating nikel pada plastic ABS

Gambar 3.b menunjukkan pengaruh waktu aktivasi palladium terhadap ketebalan lapisan bahwa semakin lama waktu aktivasi, ketebalan lapisan semakin meningkat. Pada waktu aktivasi 4 menit, ketebalan lapisan sebesar $1,766 \mu \mathrm{m}$ semakin meningkat sampai waktu aktivasi 12 menit ketebalan lapisan sebesar 2,676 $\mu \mathrm{m}$. Dapat disimpulkan, variasi waktu aktivasi palladium sangat berpengaruh terhadap ketebalan lapisan karena semakin lama waktu aktivasi palladium semakin banyak ion-ion palladium yang menempel pada permukaan plastik ABS dan akan mempengaruhi banyaknya logam nikel yang menempel pada proses electroless nickel plating.

Pada proses etsa, kandungan fosfor dan $\mathrm{pH}$ larutan electroless nickel dapat memengaruhi tingkat adhesi ion-ion logam nikel pada permukaan substrat. Dengan meningkatnya kadar palladium yang terdapat pada permukaan plastik ABS, logam nikel yang menempel akan mereket dengan lebih baik. Hal ini menyebabkan tingkat keausan menurun, kekasaran menurun, dan kekerasan serta ketebalan lapisan nikel yang dihasilkan akan meningkat dengan baik [9].

\subsection{Kekerasan Permukaan}

Pada pengujian kekasaran ini, alat yang digunakan adalah Shore Hardness Tester tipe D. Hasil pengujian dapat dilihat pada Gambar 3.3.

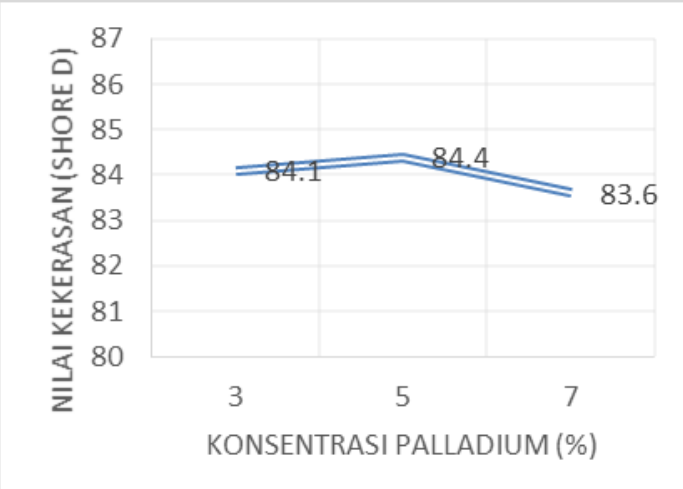

(a) Pengaruh konsentrasi larutan aktivasi palladium

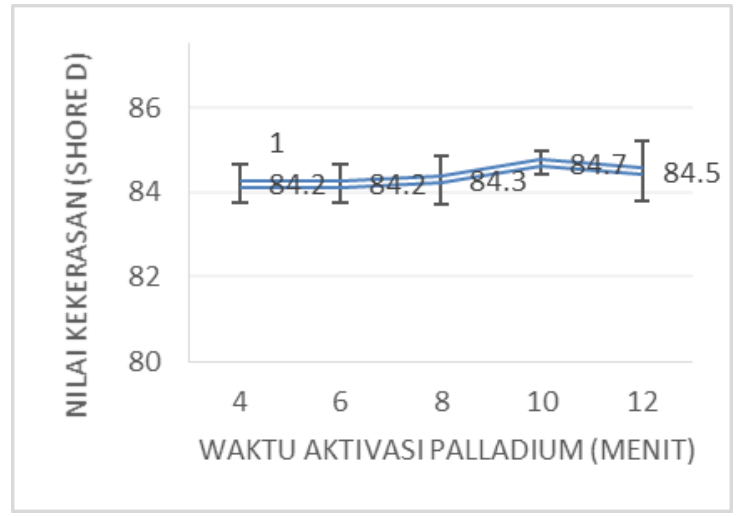

(b) Pengaruh waktu aktivasi pada larutan palladium

Gambar 3.3. Grafik nilai kekerasan setelah proses elektrolessplating nikel pada plastic ABS

Berdasarkan data hasil pengujian pada Gambar 3.3 a, nilai kekerasan lapisan untuk konsentrasi katalis palladium $3 \mathrm{ml} 84,1 \mathrm{SHN}$. Setelah konsentrasi katalis ditingkatkan menjadi $5 \mathrm{ml}$, nilai kekerasan meningkat menjadi 84,4 SHN. Namun, ketika konsentrasi 
ditingkatkan menjadi $7 \mathrm{ml}$, nilai kekerasan menurun menjadi 83,6 SHN. Gambar $3.3 \mathrm{~b}$ adalah hasil pengujian kekerasan pada variasi waktu aktivasi palladium. Nilai kekerasan untuk waktu aktivasi 4 menit sampai 12 menit berada di antara 84,2 SHN hingga 84,7 SHN tertinggi pada waktu 10 menit. Dari grafik di atas dapat diketahui, bahwa konsentrasi dan waktu aktivasi palladium tidak berpengaruh signifikan terhadap kekerasan specimen plastic ABS yang memiliki kekerasan awal 83,5 SHN. Hal ini dikarenakan fungsi dari proses aktivasi palladium adalah untuk menghasilkan permukaan plastik ABS yang bersifat katalis dengan menempati pori-pori yang dihasilkan pada proses etching. lon-ion palladium berfungsi mengikat ion-ion nikel pada proses electrolessplating. Lapisan yang dihasilkan juga relatif tipis sehingga kekerasan nikel belum signifikan meningkat nilai kekerasan specimen.

\subsection{Ketahanan Aus}

Pengujian keausan dilakukan menggunakan metode Ogoshi dengan menggunakan alat pengujian keausan Riken-Ogoshi's Universal Wear. Pengujian dilakukan dengan memberikan beban gesek dari cincin yang berputar (revolving disc) ke setiap spesimen. Pemberian beban gesekan ini akan mengambil sebagian material yang ada di permukaan benda uji dan memberikan jejak. Keausan spesifik (Ws) dihitung berdasarkan lebar keausan pada benda uji akibat gesekan piringan pengaus.

Gambar 3.4.a menunjukkan bahwa peningkatan konsentrasi larutan palladium sangat memengaruhi penurunan keausan spesifik spesimen. Pada konsentrasi palladium $3 \%$, diperoleh keausan spesifik sebesar 2,39 x 10-3 mm2/kg menjadi 0,26 × 10-3 mm2/kg pada konsentrasi $7 \%$. Peningkatan waktu aktivasi dalam larutan palladium juga menurunkan keausan spesifik dari 0,566 $\times 10-3 \mathrm{~mm} 2 / \mathrm{kg}$ dalam waktu 4 menit selanjutnya turun sampai 0,271 x 10-3 mm2/kg dalam waktu 8 menit dan untuk waktu yang lebih lama lagi penurunan keausan spesifik tidak terlalu signifikan, seperti ditunjukkan pada Gambar 3.4.b. Semakin lama waktu aktivasi palladium, semakin banyak palladium yang menempel pada permukaan plastik. Katalis palladium berfungsi sebagai aktivator sehingga pada saat electroless palladium akan mengikat nikel dengan maksimal dan menjadikan plastik lebih tahan gesekan [10]. Dari hasil tersebut, dapat disimpulkan bahwa semakin meningkatnya konsentrasi katalis palladium yang digunakan saat aktivasi, logam nikel akan lebih merekat pada permukaan plastik. Kondisi tersebut membuat lapisan lebih tahan aus karena logam nikel merekat dengan baik sehingga konsentrasi katalis palladium sangat memengaruhi hasil pelapisan karena dengan meningkatnya kadar palladium yang digunakan, logam yang menempel pada plastik akan lebih banyak dan berdampak pada hasil yang maksimal [11].

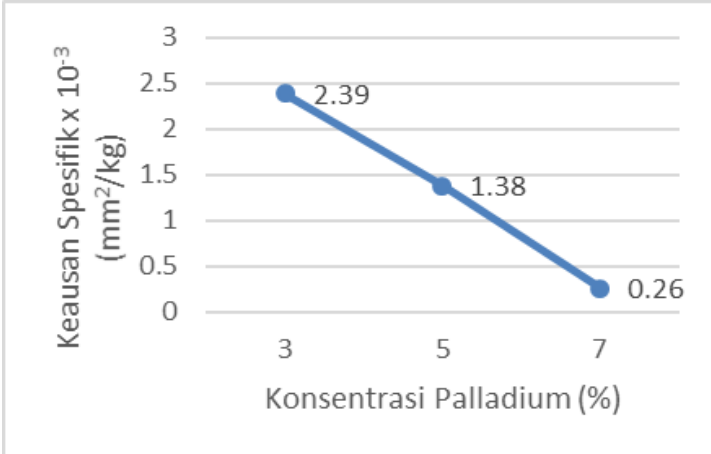

(a) Pengaruh konsentrasi larutan aktivasi palladium

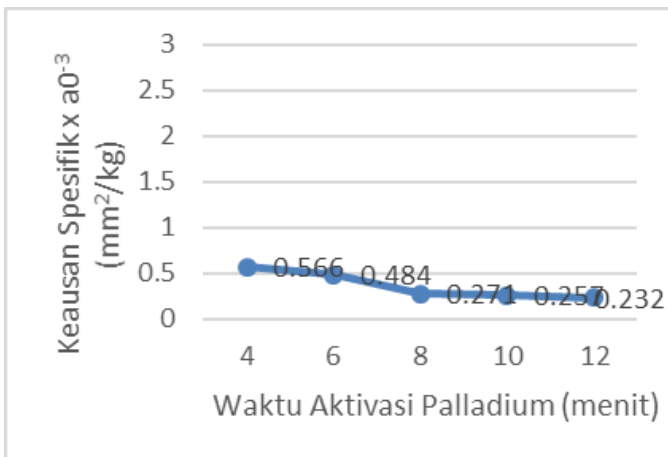

(b) Pengaruh waktu aktivasi pada larutan palladium

Gambar 3.4. Keausan spesifik lapisan setelah elektrolessplating nikel pada plastic ABS

\section{Kesimpulan}

Berdasarkan data hasil penelitian dapat diambil kesimpulan sebagai berikut:

a. Semakin besar konsentrasi dan lama waktu aktivasi palladium, ketebalan lapisan hasil electrolessplating nikel semakin besar. Pada konsentrasi $7 \%$ diperoleh ketebalan lapisan 1,83 $\mu \mathrm{m}$ dan lama aktivasi 12 menit diperoleh ketebalan 2,67 $\mu \mathrm{m}$. 
b. Peningkatan konsentrasi dan waktu proses aktivasi palladium akan menurunkan kekasaran permukaan, dari $0,525 \mu \mathrm{m}$ pada konsentrasi $3 \%$ menjadi $0,506 \mu \mathrm{m}$ pada konsentrasi $7 \%$, sedangkan waktu aktivasi 4 menit nilai kekasaran $0,840 \mu \mathrm{m}$ dan pada waktu aktivasi 12 menit nilai kekasaran $0,556 \mu \mathrm{m}$.

c. Variasi konsentrasi dan lama waktu aktivasi palladium tidak memengaruhi nilai kekerasan secara signifikan karena tebal lapisan yang diperoleh sangat tipis. Hasil penelitian diperoleh nilai kekerasan tertinggi pada konsentrasi $5 \%$ sebesar $84,4 \mathrm{SDH}$ dan waktu aktivasi 10 menit sebesar 84,7 SDH.

d. Penambahan konsentrasi dan lama aktivasi akan meningkatkan ketahanan aus. Pada lama aktivasi 4 menit, nilai keausan spesifik $0,566 \times 10^{-3} \mathrm{~mm}^{2} / \mathrm{kg}$ menjadi $0,232 \times 10^{-3}$ $\mathrm{mm}^{2} / \mathrm{kg}$ pada 12 menit, dan pada konsentrasi $3 \%$, nilai keausan spesifik $2,39 \times 10^{-3}$ $\mathrm{mm}^{2} / \mathrm{kg}$ menjadi $0,26 \times 10^{-3} \mathrm{~mm}^{2} / \mathrm{kg}$ pada konsentrasi $7 \%$.

Peningkatan konsentrasi dan lama waktu aktivasi palladium akan meningkatkan pengendapan ion palladium sehingga memudahkan ion nikel terikat dan menempel pada permukaan plastik. Hal ini menyebabkan peningkatan ketebalan lapisan dan ketahanan aus walaupun nilai kekesaran tidak banyak berubah dan menurunkan kekasaran permukaan. Dari hasil penelitian, diperoleh hasil optimal untuk aktivasi palladium dengan konsentrasi $7 \%$ dengan waktu aktivasi 6 menit dan konsentrasi 3\% dengan waktu aktivasi 12 menit.

\section{Daftar Pustaka}

[1] Equbal, A., and Sood. K.A. Metallization on FDM Parts Using the Chemical Deposition Technique. Coatings, 2014; 4 (3): 574-586.

[2] Mujiarto, I. Sifat dan karakteristik material plastik dan bahan aditif. Traksi, 2005; 3(2): 65.

[3] Santhiarsa, N. Pengaruh Temperatur Larutan dan Waktu Pelapisan Elektroles Terhadap Ketebalan Lapisan Metal Dipermukaan Plastik ABS. Prosiding Konferensi Nasional Engineering Perhotelan, 2016; VII 4 (1): 22.

[4] Shao, Z., Z. Cai, R. Hu, and S. Wei., The study of electroless nickel plating directly on magnesium alloy. Surface \& Coating Technology, 2014; 249: $42-47$.

[5] Tang, X., M. Cao, C. Bi, L. Yan, and B. ZhangResearch on a New Surface Activation Process for Electroless Plating. Materials Letters . 2007; 62: 1089-1091.

[6] Gui-Xiang., W., Li. N., Li. D., "Effect of Palladium ions in the chemical etching solution." Journal of University of Science and Technology Beijing Mineral Metallurgy Material, 2007; 14(3):286-289

[7] Olivera, S., H. B. Muralidhara, K. Venkatesh, K. Gopalakrishna, and C. S. Vivek., Plating on acrylonitrile-butadiene-styrene (ABS) plastic. Springer Science 2016: 51 (8): 3657-3674.

[8] Yulianto, S. R., and E. Widodo, "Analisa Pengaruh Variasi Temperatur Proses Pelapisan Nikel Khrom Terhadap Kualitas Ketebalan Dan Kekerasan Pada Baja ST 40." SNFT UMSIDA, 2013;145-149.

[9] Domenech, S.C., E. Lima Jr, V. Drago, J.C. De Lima, N.G. Borges Jr, A.O.V Avila, and V. Soldi. Electroless Plating of Nickel-Phosphorous on Surface-Modified Polyethylene terephthalate Films." Applied Surface Science 220. 2003; 1-4: 238-250.

[10] Krulik, G. A. "Tin-Palladium Catalysts for Electroless Plating. Platinum Metals Review 6. 1982; $2:$ 58-64.

[11] Wang, G. X., N. Li, H. L. Hu, and Y. C. Yu. Process of Direct Copper Plating on ABS Plastics. Applied Surface Science 253. 2006; 2: 480-484. 